УДК 338.23

https://doi.org/10.24866/1813-3274/2021-2/31-41

В. П. Микитчук ${ }^{1}$, Северо-Восточный государственный университет,

г. Магадан, Россия

E-mail: mikitchuk72@mail.ru

Orcid:0000-0002-6783-1824

\title{
ИНВЕСТИЦИИ В ОБЩЕСТВЕННЫЙ СЕКТОР КАК ВОЗМОЖНОСТЬ ПРИВЛЕЧЕНИЯ ФИНАНСИРОВАНИЯ НА РЕАЛИЗАЦИЮ СОЦИАЛЬНЫХ ПРОЕКТОВ В РЕГИОНАХ И МУНИЦИПАЛИТЕТАХ
}

Аннотация. В статье рассматриваются ключевые особенности становления общественного сектора как элемента публичного управления в стране. Подчёркивается, что в настоящее время процесс поддержки общественного сектора носит диссипативный и диверсифицированный характер. Осуществлён авторский сравнительный анализ показателей привлечения грантового финансирования в два региона Российской Федерации - Белгородскую область, где инвестиции в инфраструктуру общественного сектора осуществляются уже долгие годы, и Магаданскую, где этот процесс находится на начальном этапе. Период проведения исследования составил 2017-2020 гг., а именно 9 конкурсов Грантов президента, при этом учитывались только проекты-победители. Автором разработаны индикаторы развития общественного сектора, позволяющие определить приоритеты инвестиционный стратегии для привлечения финансирования в социальную сферу региона и муниципалитета. К числу данных показателей были отнесены индекс включённости в грантовые программы, индекс социальной доходности, активность деятельности ресурсного центра для некоммерческих организаций (НКО), уровень проектных компетенций у представителей НКО, доля НКО муниципалитетов, участвующих в конкурсах грантов. На основе вышеизложенного предложены рекомендации, которые в разной степени могут быть скомбинированы в инвестиционных стратегиях регионов и муниципалитетов.

\footnotetext{
${ }^{1}$ Виталий Павлович Микитчук, кандидат экономических наук, доцент кафедры экономики ФГБОУ ВО «Северо-Восточный государственный университет» (СВГУ), г. Магадан, Россия. Orcid:0000-00026783-1824.

Для циитирования: Микитчук В. П. Инвестиции в общественный сектор как возможность привлечения финансирования на реализацию социальных проектов в регионах и муниципалитетах // АзиатскоТихоокеанский регион: экономика, политика, право. 2021. №. 2. C. 31-41. DOI https://doi.org/10.24866/1813-3274/2021-2/31-41.
}

(C) Микитчук В. П., 2021 
Ключевые слова: инвестиции в общественный сектор, социальная сфера, социальное проектирование, экономика, гранты, государственное управление, инвестиционные ресурсы, некоммерческие организации (НКО), Белгородская область, Магаданская область, публичное управление, грантодатель, индекс социальной доходности.

V. P. Mikitchuk ${ }^{1}$, North-Eastern State University, Magadan, Russia

E-mail: mikitchuk72@mail.ru

\section{INVESTMENTS IN THE PUBLIC SECTOR AS AN OPPORTUNITY TO ATTRACT FINANCING FOR THE IMPLEMENTATION OF SOCIAL PROJECTS IN REGIONS AND MUNICIPALITIES}

Adstract. The article examines the key features of the formation of the public sector as an element of the country's public administration. It is emphasized that the process of supporting the public sector is currently dissipative and diversified. The author's comparative analysis of the indicators of attracting grant financing in two regions of the Russian Federation - the Belgorod region, where investments in the infrastructure of the public sector have been carried out for many years; and Magadan, where this process is at its initial stage. The period of the study included 2017-2020, namely 9 presidential grants competitions, while only winning projects were taken into account. The author has developed indicators of the development of the public sector, allowing determining the priorities of the investment strategy to attract funding to the social sphere of the region and the municipality. These indicators included the index of involvement in grant programs, the index of social profitability, the activity of the resource centre for non-profit organizations (NPO), the level of project competencies among NPO representatives, the share of NPO of municipalities participating in grant competitions Based on the aforesaid, recommendations are proposed that can be combined to varying degrees in investment strategies of regions and municipalities.

Keywords: investments, public sector, social sphere, social engineering, economics, grants, public administration, investment resources, non-profit organizations (NPO), Belgorod region, Magadan region, public administration, grantor, social profitability index.

\footnotetext{
${ }^{1}$ Vitaly Pavlovich Mikitchuk, Candidate of Economic Sciences, Associate Professor of the Department of Economics, North-Eastern State University (SVSU), Magadan, Russia.

For citing: Mikitchuk V. P. Investments in the public sector as an opportunity to attract financing for the implementation of social projects in regions and municipalities // PACIFIC RIM: Economics, Politics, Law. 2021. No 2. P. 31-41. DOI https://doi.org/10.24866/1813-3274/2021-2/31-41.
} 
Введение. В последние годы в России всё большее распространение получает концепция «публичного управления» или «публичной власти». Так, в 2020 г. термин «Публичная власть» даже был закреплён в поправках в Конституцию РФ. Постепенный переход от институционализированной и нормализованной системы государственного и муниципального управления к новой форме кооперации определён многочисленными социальными трансформациями: ростом роли новых субъектов, повсеместной дигитализацией, преобразованием структуры общественных интересов.

По мнению Г. Л. Купряшина, в этих условиях возникает необходимость в консолидации и коммуникации всех структур, направленных на решение социальных проблем. В общем виде публичное управление он определяет как систему кооперации государственных, муниципальных, некоммерческих и смешанных структур, призванную обеспечить удовлетворение общественных интересов и решение социальных проблем [4].

В свою очередь, В. Б. Слатина и И. А. Ботанина отмечают, что современные тренды совершенствования государственного управления ориентированы на повышение его эффективности и гибкости в ответ на новые вызовы, возникающие вследствие глобализации, децентрализации и менеджериализации [6].

Ключевым в данной тенденции является расширение числа субъектов публичного управления - структур, способных не только перенимать отдельные функции государственной политики, в первую очередь социальные, но и эффективно реализовывать их.

Таким образом, в систему публичного управления также включаются общественные некоммерческие организации, которые путём реализации социальных проектов обеспечивают исполнение отдельных государственных функций. Особенно важно подчеркнуть, что процесс налаживания диалога между общественным сектором и органами власти сопровождался активным внедрением инструментария социального проектирования в деятельность общественных организаций.

Однако данный процесс носит, во-первых, диссипативный характер деятельности общественного сектора. Различные НКО, участвуя в развитии социальной сферы, ориентируется прежде всего на собственные накопленные практики и экзистенциальный опыт. Во-вторых, существует высокая дифференцированность между регионами, как по уровню развития региона, так и по механизмам его поддержки.

Таким образом, основная цель данной статьи заключается в исследовании наиболее эффективных инструментов инвестирования в региональный и муниципальный общественный сектор, которые позволят привлечь ресурсы для проектов НКО, направленных на развитие социальной сферы.

Результаты исследования. С 2006 г. для российских общественных организаций на конкурсной основе распределяются финансовые средства для реализации 
социальных проектов. Однако только с 2017 г. действует единый оператор - Фонд президентских грантов, распределяющий финансирование между общественными организациями из всех субъектов РФ. В 2020 г. Фонд поддержал свыше 5000 социальных проектов на сумму более чем 10 млрд руб. а также выделил 3 млрд руб. на субсидирование региональных конкурсов социальных проектов [8].

Для проведения анализа эффективности развития общественного сектора было выбрано 2 региона. Белгородская область - как регион, регулярно входящий в топы рейтингов развития инфраструктуры НКО и общественного сектора. А также Магаданская область, где на некоторые конкурсы президентских грантов вообще не было зарегистрировано ни одной заявки-победителя.

Период исследования составил 2017-2020 гг., а именно 9 конкурсов Грантов президента (учитывались только проекты-победители). По итогам анализа победу в конкурсе за исследуемый период одержали 234 социальных проекта в Белгородской области и 48 проектов в Магаданской области. Стоит отметить, что в Белгородский регион в общей сложности за 4 года на развитие социальной сферы было привлечено 262873 829,5 руб., а в Магаданский почти в 6 раз меньше 44430 631,74. Однако помимо статичных показателей гораздо больший интерес представляет анализ динамики развития инфраструктуры общественного сектора, представленный в табл. 1.

Таблицуа 1

\section{Динамика основных показателей финансовой поддержки общественного сектора [8]}

\begin{tabular}{|c|c|c|c|c|}
\hline Регион & 2017 & 2018 & 2019 & 2020 \\
\hline \multicolumn{5}{|c|}{ Число заявок-победителей (шт.) } \\
\hline Белгородская область & 14 & 33 & 39 & 148 \\
\hline Магаданская область & 12 & 11 & 12 & 13 \\
\hline \multicolumn{5}{|c|}{ Общая сумма привлечённых средств (тыс. руб.) } \\
\hline Белгородская область & 30655,23 & 50017,91 & 54381,34 & 127819,35 \\
\hline Магаданская область & 12352,85 & 8561,401 & 13030,46 & 10485,92 \\
\hline \multicolumn{5}{|c|}{ Средняя сумма полученного гранта (тыс. руб.) } \\
\hline Белгородская область & 2189,66 & 1515,70 & 1394,39 & 863,64 \\
\hline Магаданская область & 1029,40 & 778,31 & 1085,87 & 806,61 \\
\hline
\end{tabular}

В построенной табл. 1 приведены три показателя за период с 2017 г. по 2020 г. А именно: число заявок, получивших поддержку в рамках конкурса грантов Президента; общая сумма средств, выделенная на грантовую поддержку проектов в данном регионе; средняя сумма гранта, которая рассчитывается как частное между общей выделенной суммой и числом поддержанных проектов по данной области. 
Приведённый массив данных позволяет сделать несколько выводов по каждому из субъектов. Относительно Магаданской области целесообразно отметить почти полное отсутствие позитивной динамики, как в числе проектов-победителей, так и в объёмах привлечённых средств. С одной стороны, это может быть вызвано тем фактом, что потенциал социального проектирования НКО Магаданской области на данном этапе уже исчерпан и общественный сектор региона приложил все возможные усилия для участия в конкурсах. С другой стороны, за отсутствием позитивной динамики может скрываться целый ряд причин объективного и субъективного характера: недостаток у менеджеров профессиональных компетенций в области проектного управления; отсутствие социальных проблем, которые можно решить методом социального проектирования; низкий уровень поддержки ресурсных центров НКО и региональных структур.

Белгородская область демонстрирует более позитивные тенденции. Так, значительно возросло число проектов-победителей, поданных от НКО региона. За последние 4 года практически увеличилась сумма средств, привлечённых на реализацию социальных проектов.

Вместе с тем, существенно снизилась сумма гранта, которая стала меньше даже аналогичного показателя Магаданской области. Результатом этого явились несколько специфичных решений, которые были использованы органами государственной и муниципальной власти региона. Во-первых, если ранее подготовку и подачу инициативных заявок осуществляли прежде всего «организациимастодонты», которые на протяжении многих лет ведут активную работу, то в последние годы органы государственной власти и муниципального управления стали привлекать малые НКО к реализации небольших социальных проектов. Целесообразно отметить, что проходной балл для проектов финансированием до 500 тыс. руб. составляет всего 60 баллов, что для малых НКО не представляется неодолимым препятствием. Так, согласно данным Фонда президентских грантов, в 2018 и 2019 гг. от Белгородской области более половины организаций участвовали в подобных инициативах впервые. Это подтверждается и статистическими данными: если в 2017 г. от региона подали всего 40 заявок, то в 2018 г. их было уже 238, а в 2019 г. - 411. Налицо кратное увеличение числа организаций, участвующих в конкурсе [8].

Во-вторых, был создан ресурсный центр НКО, на постоянной основе обеспечивающий проведение методических семинаров для общественного сектора, по проблематике подготовки заявки, написания календарного плана, составления бюджета и т. д. [7].

Ещё одним преимуществом выступает привлечение к проведению таких семинаров как профессиональных проект-менеджеров и управленцев (Департамент внутренней и кадровой политики Белгородской области и Высшая школа управле- 
ния Белгородского государственного национального исследовательского университета), так и представителей НКО, презентующих свой успешный опыт реализации президентских проектов (Центр социальных инициатив «Вера»).

Наконец, в-третьих, серьёзный акцент был сделан на НКО муниципальных образований региона. В своих исследованиях В. П. Бабинцев акцентирует внимание на том, что до настоящего времени общественный сектор муниципалитетов рассматривался, скорее, как неинституционализированная самоорганизация населения, не ограниченная такими категориями, как некоммерческое объединение или автономная некоммерческая организация [1].

Вместе с тем, в Белгородской области большое внимание уделялось именно НКО муниципальных образований, где при содействии местных администраций регулярно проходили методические встречи с представителями общественного сектора [2]. И именно в муниципальных образованиях заинтересованы в реализации небольших социальных проектов, направленных на решение локальных проблем территорий.

Именно этими факторами и причинами обусловлено как общее увеличение числа заявок, в т.ч. и победителей, так и снижение средней суммы грантов, т.к. на первый план в регионе стало выходить решение локальных проблем.

В Магаданской области также функционирует региональный центр поддержки НКО - Ресурсный центр поддержки общественных инициатив. Однако методические семинары проходят недостаточно часто, и их проведение наладилось только в последние месяцы. Говорить о привлечении общественного сектора из муниципальных районов вообще пока не приходится. Не хватает и передачи успешного опыта теми $\mathrm{HКО,} \mathrm{которые} \mathrm{уже} \mathrm{являлись} \mathrm{победителями} \mathrm{Конкурса} \mathrm{президентских} \mathrm{грантов.}$

В данном контексте целесообразно подчеркнуть, что прямое сравнение двух совершенно разных регионов, с серьёзными диспропорциями как в составе населения, так и в количестве НКО, не может дать полной картины успешности инвестиций в общественный сектор. В этой связи, необходима разработка системы индексов показателей, отражающих эффективность общественного сектора в каждом конкретном регионе или муниципалитете.

Обсуждение результатов. Согласно данным Министерства юстиции РФ, в Белгородской области на данный момент зарегистрировано $1843 \mathrm{HKO}$, а в Магаданской области их число составляет 384 [3]. По нашему мнению, именно исходя из численности НКО необходимо осуществлять расчёт эффективности общественного сектора.

Первым показателем является индекс числа НКО - победителей конкурса от общего количества организаций общественного сектора в регионе, который может быть рассчитан по следующей формуле:

$$
I_{\text {өключейности }}=\frac{\text { число заявок }- \text { победителей }}{\text { обијее число НКО региона }} .
$$


Микитчук В. П. Инвестиции в общественный сектор как возможность привлечения финансирования на реализацию социальных проектов в регионах и муниципалитетах

Вторым показателем может стать индекс средней социальной доходности НКО, исходя из объёма привлеченных грантовых средств на одну общественную организацию региона:

$$
I_{\text {сопиальной доходности }}=\frac{\text { годовая суииа приетеченных средсе }}{\text { обицее число НКО ресиона }} \text {. }
$$

Два этих показателя уже могут в полной мере отражать, насколько НКО региона включены в процессы социального проектирования и грантовой поддержки, и, что ещё немаловажно, определить приоритеты дальнейшего инвестирования в общественный сектор. Расчёты индексов для двух рассматриваемых регионов представлены в табл. 2.

Таблица 2

Динамика основных индексов развития общественного сектора [8]

\begin{tabular}{|c|c|c|c|c|}
\hline Регион & 2017 & 2018 & 2019 & 2020 \\
\hline \multicolumn{5}{|c|}{$I_{\text {включённости }}$} \\
\hline Белгородская область & 0,0076 & 0,0179 & 0,0212 & 0,0803 \\
\hline Магаданская область & 0,0313 & 0,0286 & 0,0313 & 0,0339 \\
\hline \multicolumn{5}{|c|}{$I_{\text {социальной доходности }}$} \\
\hline Белгородская область & 16633,33 & 27139,4 & 29506,97 & 69353,96 \\
\hline Магаданская область & 32168,89 & 22295,32 & 33933,48 & 27307,09 \\
\hline
\end{tabular}

Как видно из табл. 2, отставание Магаданской области по всем позициям составляет в 2-3 раза. Расчётные показатели уже не дают возможности сделать скидку на небольшое число общественных организаций в регионе и несоразмерный объём финансовых средств, привлекаемых в рамках проектов-победителей.

В этой связи, для каждого из регионов необходимы уникальные стратегии и механизмы инвестирования в общественный сектор, несмотря на то, что, по мнению С. В. Наумова, «в современной России достаточно длительное время не приживаются механизмы эффективной мобилизации и применения инвестиционных ресурсов в общественном секторе экономики, с успехом оправдавшие себя во многих других частях света» [5].

Тем менее, именно на современном этапе есть все возможности создать эффективную систему инвестирования в инфраструктуру общественного сектора, достаточно гибкую для изменения от региона к региону.

Безусловно, недостаточно только повышать компетентность сотрудников, социально-ориентированных НКО в области проектного управления. Необходимо выстраивать комплексную стратегию инвестирования в общественный сектор, основанную на оценке множества элементов [9]. 
Таким образом стратегия инвестирования в развитие общественного сектора региона или муниципалитета должна строиться на следующих элементах (табл. 3).

Таблица 3

\section{Показатели для выбора стратегии инвестирования в общественный сектор региона/муниципалитета}

\begin{tabular}{|l|l|l|}
\hline № & \multicolumn{1}{|c|}{ Показатель } & \multicolumn{1}{c|}{ Описание } \\
\hline 1 & I вклюённости & $\begin{array}{l}\text { Отражает, насколько общественные организации } \\
\text { включены в процессы участия в грантовых } \\
\text { конкурсах }\end{array}$ \\
\hline 2 & I социальнй доходнсти & $\begin{array}{l}\text { Демонстрирует средний объём финансирования, } \\
\text { который привлекают НКО в рамках грантовых } \\
\text { конкурсов }\end{array}$ \\
\hline 3 & $\begin{array}{l}\text { Активность деятельности } \\
\text { ресурсного центра для НКО }\end{array}$ & $\begin{array}{l}\text { Определяется наличием ресурсного центра для } \\
\text { НКО, объёмами консультационной, информаци- } \\
\text { онной, организационной и иной поддержки, чис- } \\
\text { лом реализуемых методических семинаров и т. д. }\end{array}$ \\
\hline 4 & $\begin{array}{l}\text { Уровень проектных } \\
\text { компетенций у представителей } \\
\text { НКО }\end{array}$ & $\begin{array}{l}\text { Определяется уровнем умений, навыков и знаний } \\
\text { представителей НКО в области социального про- } \\
\text { ектирования и подготовки грантовых заявок }\end{array}$ \\
\hline 5 & $\begin{array}{l}\text { Доля НКО муниципалитетов, } \\
\text { участвующих в конкурсе }\end{array}$ & $\begin{array}{l}\text { Демонстрирует, насколько общественный сектор } \\
\text { территорий включён в процессы получения гран- } \\
\text { тов, социального проектирования и т. д. }\end{array}$ \\
\hline
\end{tabular}

Нами осознанно не включён такой показатель, как доля НКО, подавших заявки на конкурс. Уже сейчас, в условиях формализма и обязательности достижения зачастую завышенных показателей, на конкурс подаются заведомо проигрышные или пустые заявки, только для того, чтобы достигнуть запланированного значения общего числа заявок от региона.

Заключение. Выбор конкретной стратегии должен быть основан на совокупности различных методов и инструментов, некоторые из которых подойдут тем регионам, где общественный сектор находится на начальном этапе своего развития, а другие путём разностороннего развития достигли значимых результатов. Нами разработан и предлагается к реализации набор методов и форм, которые могут изменяться в совершенно различных стратегиях:

1. Составление чёткого реестра НКО, доступ к которому будет иметь не только Министерство юстиции РФ, но и субъекты региональной администрации. Это позволит отслеживать неэффективные «НКО-нулёвки», значительно снижающие общую статистику участия в конкурсах, а также проводить массовую рассылку о грантовых конкурсах, формах поддержки и методических мероприятиях. 
2. Создание регионального ресурсного центра поддержки НКО, который должен оказывать юридическую, информационную, экспертную, консультационную и иную помощь НКО при разработке заявок. Вызывает интерес опыт Белгородской области, где местный ресурсный центр на безвозмездной основе создаёт простейшие веб-сайты для НКО, поскольку информационная открытость является одним из важнейших критериев оценки грантовых заявок.

3. Регулярное проведение методических семинаров, где представители НКО смогут познакомиться с особенностями подготовки заявки, составления календарного плана, разработки бюджета и, что не маловажно, отчётности по проекту.

4. Привлечение муниципальных НКО к реализации локальных социальнозначимых проектов. В последние годы основным приоритетом Фонда президентских грантов является поддержка социальных проектов именно сельских территорий, где местные проблемы имеют особое значение для жителей.

5. Активизация сотрудничества с региональными вузами. Так, например, видится целесообразным включение в вариативную часть образовательных программ специальностей «Государственное и муниципальное управление» и «Менеджмент» дисциплины «Социальное проектирование», открытие программ дополнительного образования и повышения квалификации для представителей НКО по направлению «Социальное проектирование», а также открытие образовательной программы магистратуры «Управление социальными проектами».

6. Большое значение имеет привлечение к реализации проектов социальной сферы неявных субъектов, например, территориальных общественных самоуправлений (ТОС). Только за первый конкурс 2021 г. 61 территориальное общественное самоуправление, зарегистрированное как юридическое лицо, получило поддержку Фонда президентских грантов. Активная политика властей по официальной регистрации ТОС может стать подспорьем данному направлению.

7. Малое внимание уделяется православным храмам и приходам, которые также могут являться объектами получения государственной поддержки. Так 52 прихода в 2021 г. уже получили поддержку. При этом особое внимание грантодатели уделяют сельским храмам, которые могут стать своеобразным центром духовного и социального возрождения сельской территории.

Таким образом, инвестирование в общественный сектор является одним из долгосрочных механизмов привлечения финансовых средств в социальную сферу региона. Государственным и муниципальным органам власти необходимо уже сейчас, исходя из текущей ситуации, выбирать наиболее перспективные стратегии инвестирования в развития НКО.

Вместе с тем, в последние месяцы появляется всё больше «профессиональных» организаций, предлагающих обеспечение доработки заявки до её победы в конкурсе. Подобным тенденциям должна противодействовать слаженная и эффективная 
работа органов власти. В ином случае, реализация общественным сектором проектов в социальной сфере превратится в ещё один источник коммерциализации.

\section{Список источников и литературы}

1. Бабинцев, В. П. Консолидационный потенциал муниципальных образований: проблемы оценки и формирования // Управление в XXI веке : сборник статей по материалам Международной научно-практической конференции. - Белгород : Издательский Дом «Белгород», 2016. - С. 192-196.

2. В округе состоялся межокружной семинар «Разработка социально значимых проектов в приграничных муниципалитетах». - URL: https://www.graivoron.ru/publicati ons/2-iyunya-2019-goda-v-gorode-grajvorone-sostoyalsya/ (дата обращения: 01.02.2021).

3. Информационный портал деятельности некоммерческих организаций Министерства юстиции РФ. Информация о зарегистрированных некоммерческих организациях. - URL: http://unro.minjust.ru/NKOs.aspx(дата обращения: 01.02.2021).

4. Купряшин, Г. Л. Публичное управление // Политическая наука. - 2016. № 2. - C. 101-129.

5. Наумов, С. В. Инвестиции в общественном секторе экономики и дефицит определенности на пути освоения Россией современных экономических механизмов // Terra Economicus. - 2015. - № 13. - C. 55-66.

6. Слатинов, В.Б. Публичное управление в глобализирующемся мире: в поисках эффективной бюрократии / В. Б. Слатинов, И. А. Батанина // Среднерусский вестник общественных наук. - 2016. - № 11. - С. 97-103.

7. Состоялся семинар для социально ориентированных некоммерческих организаций Белгородской области. - URL: http://www.csi-vera.ru/press-centr/30noyabrya-2016-goda-sostoyalsya-seminar-dlya-soc/(дата обращения: 01.02.2021).

8. Фонд президентских грантов. - URL: https://xn--80afcdbalict6afooklqi5o.xn-p1ai/ (дата обращения: 01.02.2021).

9. Competencies of project managers in international NGOs: Perceptions of practitioners / S. Briyere, D. Proulx, F. Navaro, L. Laporte // International Journal of Project Management. - 2015. - № 33. - P. 116-125.

\section{References}

1. Babintsev V. P. Konsolidatsionnyi potentsial munitsipal'nykh obrazovanii: problemy otsenki i formirovaniya [Consolidation potential of municipalities: problems of assessment and formation]. In: Upravlenie $v$ XXI veke: sbornik statei po materialam Mezhdunarodnoi nauchno-prakticheskoi konferentsii [Management in the XXI century: a collection of articles based on the materials of the International Scientific and Practical Conference]. Belgorod: Izdatel'skii Dom «Belgorod», 2016, pp. 192-196. 
2. An interdistrict seminar «Development of socially significant projects in border municipalities». Available at: https://www.graivoron.ru/publications/2-iyunya-2019goda-v-gorode-grajvorone-sostoyalsya/ (accessed 01 February 2021). (In Russian).

3. Information portal of the activities of non-profit organizations of the Ministry of Justice of the Russian Federation. Information about registered non-profit organizations. Available at: http://unro.minjust.ru/NKOs.aspx (accessed 01 February 2021). (In Russian).

4. Kupryashin G. L. Publichnoe upravlenie [Public administration]. Politicheskaya nauka, 2016, no. 2, pp. 101-129.

5. Naumov S. V. Investitsii v obshchestvennom sektore ekonomiki i defitsit opredelennosti na puti osvoeniya Rossiei sovremennykh ekonomicheskikh mekhanizmov [Investments in the public sector of the economy and the lack of certainty on the way of Russia's development of modern economic mechanisms]. Terra Economicus, 2015, no. 13, pp. 55-66.

6. Slatinov V. B., Batanina I. A. Publichnoe upravlenie v globaliziruyushchemsya mire: $\mathrm{v}$ poiskakh effektivnoi byurokratii [Public administration in a globalizing world: in search of an effective bureaucracy]. Srednerusskii vestnik obshchestvennykh nauk, 2016, no. 11, pp. 97-103.

7. A seminar for socially oriented non-profit organizations of the Belgorod region was held. Available at: http://www.csi-vera.ru/press-centr/30-noyabrya-2016-godasostoyalsya-seminar-dlya-soc/ (accessed 01 February 2021). (In Russian).

8. Presidential Grants Fund. Available at: https://xn--80afcdbalict6afooklqi5o.xn-p1ai/ (accessed 01 February 2021). (In Russian).

9. Briyere S., Proulx D., Navaro F., Laporte L. Competencies of project managers in international NGOs: Perceptions of practitioners. International Journal of Project Management, 2015, no. 33, pp. 116-125. 